"MERIT MAKER” (“MERIT MAKER” is stand for Management , Environment, Resuscitation, Information, Trainning (survivalswimming), Media ,Advocacy/policy , Kindergarten , Education and Research ) MERIT MAKER were cover every district in Surin Province

Conclusions Now, we have the best practice in school and set a leader student to be a coach helper and also help friends in survival swimming program. Moreover, we have developed a survival swimming program for 900 trainers from every district, cooperate in school program.In community have prevent on risk resources, have poster and equipment to halp people who wsa drowning. All of this is a concrete success that all school can apply, teach in the process of teamwork and to solve the problem of drowning in Surin. The 7 years of success, between 2010-2015, is our proud. Everyone voluntarily helps children from drowning. The goal is to reduce death rate of drowning lower than 6.5 per 100,000 childrens below 15 years old within 2018. Children can learn survival swimmimg in primary school, can float in water, and know how to help people who drowning.

\section{PROBABILITY OF DROWNING DURING CHILDHOOD IN BANGLADESH}

1,2Abu Talab, ${ }^{3}$ Michael Linnan, 1,2 Aminur Rahman, 1,2 Fazlur Rahman, 1,2 2 aidur Rahman Mashreky. 'Centre for Injury Prevention Research, Bangladesh (CIPRB); ${ }^{2}$ International Drowning Research Centre - Bangladesh (IDRCB); ${ }^{3}$ The Alliance for Safe Children (TA SC)

\subsection{6/injuryprev-2016-042156.1013}

Introduction There are many drowning studies in children that have the potential to allow calculation of the risk or probability of drowning during specific periods of childhood. However, almost none of them include a nationally representative population of children and are large enough to contain enough drowning deaths to have statistical precision in estimating the per-yearof childhood risk of drowning. The Bangladesh Health and Injury Survey (BHIS) allows just such an estimate to be calculated, which puts an actual probability of drowning by year of childhood for children in Bangladesh.

Methods The mortality experience from the child sample from BHIS was examined. A life table was constructed from the child dataset which showed the probability of survival by each year of childhood according to cause of mortality.

Results 169 deaths from drowning occurred in children in BHIS. The multiple decrement life-table analysis which shows age specific probabilities of drowning for children in Bangladesh will be presented at WCDP.

Conclusions The annual risk of dying for children in Bangladesh is already known from the census and other surveys and is high compared with high income countries. The cause-specific mortality risk calculated from the BHIS survey dataset shows that drowning is the largest risk of death from a single cause to children who survive infancy in Bangladesh through their 18th birthday, when they become adults.

Acknowledgements Centre for Injury Prevention and Research Bangladesh (CIPRB)
1014 RESCUE AND EMERGENCY MANAGEMENT OF A WATER RELATED DISASTER: EXPERIENCE FROM BANGLADESH

${ }^{1}$ Abu Sayeed Abdullah, ${ }^{1}$ Shafkat Hossain, ${ }^{1,2}$ Animesh Biswas. ${ }^{1}$ Centre for Injury Prevention and Research, Bangladesh (CIPRB); ${ }^{2}$ Orebro University

\subsection{6/injuryprev-2016-042156.1014}

Background The Padma is one of the largest rivers where thousands of people cross this river every day using boats, launches and ferries. However, the numbers of launce and ferry are insufficient than required. In maximum cases the launches are overloaded with passengers. The authorities do not strictly maintain the rules. A tragic disaster occurred on 22 February 2015 when a cargo vessel hit the launch in the Padma near Paturia launch terminal of Manikganj in Bangladesh and at least 79 people, including 14 children and 28 women, died and over 50 went missing with over 200 passengers on board. The study expresses the practice of rescue process and emergency management services provided in the event.

Methods Qualitative methods including in-depth interviews and a focus group discussion was used to collect data. The daily newspaper reports and related documents were reviewed.

Results On 11:40 am the launch sank in mid-river within 15 minutes after it left the terminal and collided with a cargo vessel. The launch was carrying 200 passengers though its capacity was 140. Around 100 passengers were either rescued or swam around half kilometre to reach the shore. The local people started rescuing passengers immediately after the accident with the help of boats and trawlers from both side. Around 150 members of different government rescue agencies participated in the rescue operation from 12:00 noon to mid night. A rescue vessel reached the spot from Mawa terminal around $11.00 \mathrm{pm}$ after 12 hours to salvage the sunken vessel. After 24 hours of rescue operation 70 bodies were handed over to the family members.

Conclusion The emergency management was inadequate and the authorities in the launches were irresponsible to take appropriate measures to rescue the passengers from drowning. Mass public awareness is essential to follow the rules for safe crossing the river. A national level policy is required for mass rescuing of people during water related disaster.

\section{DESIGN AND EVALUATION OF NOVEL IRISH DROWNING DATA TAXONOMIES FOR A FATALITIES DATABASE}

${ }^{1}$ Aoife Kervick, ${ }^{1}$ Sarah Summerville, ${ }^{2}$ Dani Dix, ${ }^{2}$ Thomas Walters, ${ }^{3}$ Roger Sweeney, ${ }^{1}$ Kiran Sarma. ${ }^{1}$ National University of Ireland, Galway, Ireland; ${ }^{2}$ Royal National Lifeboat Institution, United Kingdom; ${ }^{3}$ rish Water Safety, Ireland

\subsection{6/injuryprev-2016-042156.1015}

Background In the Republic of Ireland (ROI) 135 people drown annually, the majority of which are preventable deaths. Currently, substantial opportunities exist to develop upon the existing methods of managing fatality data in the ROI. The current study thus aimed to develop and evaluate a set of novel drowning data taxonomies, to better record drowning deaths in Irish waters. Improvements to this fatalities taxonomy will enhance accurate incident recording, and benefit subsequent intervention design. 